\title{
Solanum gourlayi-a Source of Cyst Nematode Resistance in Potato Breeding
}

\section{Dorota Milczarek $^{1}$ (D) Beata Tatarowska ${ }^{1} \cdot$ Jarosław Plich $^{1}$. Anna Podlewska-Przetakiewicz ${ }^{2} \cdot$ Bogdan Flis $^{1}$}

Received: 12 November 2019 / Accepted: 25 March 2020 /

Published online: 28 April 2020

(C) The Author(s) 2020

\begin{abstract}
The potato cyst nematodes (PCN) Globodera rostochiensis and G. pallida are among the most important pests causing significant yield loss in potato production. Cultivating resistant cultivars of potato is the most effective and environmentally safe method for protecting potato crops against nematodes. However, widespread cultivation of cultivars resistant to $G$. rostochiensis can affect the reproduction of $G$. pallida. Therefore, breeding for resistance to nematodes remains among the major aims of potato breeding programmes. Many wild Solanum species could be valuable sources of nematode resistance. This study examined the resistance to G. pallida identified in two accessions of the wild species Solanum gourlayi. Both accessions demonstrated resistance to pathotypes $\mathrm{Pa} 2$ and $\mathrm{Pa} 3$, but show asymmetric distribution of resistance among the progeny clones. The presented distributions of resistance scores indicate quantitative nature of resistance to G. pallida. Furthermore, this resistance is specific to each pathotype and may be controlled by different genes. We also conclude that there is a need for independent evaluation of resistance for both pathotypes of G. pallida (Pa2 and $\mathrm{Pa} 3)$.
\end{abstract}

Keywords Globodera pallida $\cdot$ Pathotypes $\mathrm{Pa} 2$ and $\mathrm{Pa} 3 \cdot$ Potato breeding $\cdot$ Solanum gourlayi

Electronic supplementary material The online version of this article (https://doi.org/10.1007/s11540-02009459-9) contains supplementary material, which is available to authorized users.

Dorota Milczarek

d.milczarek@ihar.edu.pl

$1 \quad$ Plant Breeding and Acclimatization Institute-National Research Institute, Research Centre Młochów, Platanowa 19, 05-831 Młochów, Poland

2 Plant Breeding and Acclimatization Institute-National Research Institute, Research Centre Radzików, 05-870 Błonie, Poland 


\section{Introduction}

The potato cyst nematodes (PCN) Globodera rostochiensis and G. pallida are the most important pests that feed on potato roots (Evans and Trudgill 1992). Yield loss caused by PCN is estimated to be as high as $50 \%$ (Nicol et al. 2011). Both PCN species are included in the list of quarantine pathogens in many countries (Smith et al. 1992). Growing resistant cultivars is economically the most effective and environmentally safe method for protecting potato crops against PCN (EPPO/OEPP 2004). However, the widespread cultivation of cultivars resistant to only $G$. rostochiensis may increase the reproduction of G. pallida. In recent years, the increased spread of G. pallida among populations of nematodes has been observed in Europe (Širca et al. 2012; EPPO 2012, 2013; Nježić et al. 2014). The cultivation of potato cultivars with resistance to multiple Globodera species may effectively provide protection against the wide spectrum of PCN pathotypes.

Resistance to nematodes was not initially found within Solanum tuberosum ssp. tuberosum. Thus, breeding for resistance to nematodes is based on resistance identified in other Solanum species (Dalamu et al. 2012). The dominant gene Gpa2 associated with resistance to G. pallida pathotype $\mathrm{Pa} 2$ was found in $S$. tuberosum ssp. andigena (van der Voort et al. 1999). The dominant gene $H 2$ was found in S. multidissectum, which confers resistance against G. pallida pathotype Pa1 (Dunnett 1961; Strachan et al. 2019). Quantitative resistance was identified in the wild species $S$. tuberosum ssp. andigena, together with the large effect QTL GpaIVs ${ }_{a d g}$ (Bradshaw et al. 1998; Bryan et al. 2004), and in S. vernei together with Gpa5 (van der Voort et al. 2000; Bryan et al. 2002). However, both these genes confer only partial levels of resistance to G. pallida pathotypes $\mathrm{Pa} 2$ and Pa3. Caromel et al. (2005) identified that cooperating resistance loci $G p a V^{s}{ }_{s p l}$ and $\mathrm{GpaXI}_{\text {spl }}$ originating from $S$. sparsipilum resulted in a strong hypersensitive response on the roots infected with $G$. pallida $\mathrm{Pa} 2 / 3$. However, many loci conferring resistance to $G$. pallida originate from wild species accessions that have not been introduced into advanced breeding material.

Solanum gourlayi $(\mathrm{grl}$ ) is one of the sources of resistance to G. pallida identified among accessions of wild Solanum species (Ruiz de Galarreta et al. 1998; Castelli et al. 2005). The major aim of our research was to examine the nematode resistance identified in two accessions of the wild species $S$. gourlayi.

\section{Materials and Methods}

\section{Plant Material}

Two accessions of $S$. gourlayi $(\mathrm{grl})$ were obtained in the form of seeds from the Centre for Genetic Resources, the Netherlands (CGN): CGN22342 and CGN17592. Both of these accessions were described as resistant to pathotypes $\mathrm{Pa} 2$ and $\mathrm{Pa} 3$ of $G$. pallida (CGN gene bank description n.d.; links in references). Clone $\mathrm{Sg} \mathrm{3/3}$ was obtained from seeds of accession CGN22342 ( $2 n=24$ chromosomes), and clone $\mathrm{Sg} 2 / 7$ was obtained from seeds of accession CGN17592 $(2 n=24$ chromosomes). The resistance of these clones was 
confirmed in a glasshouse test, and then these clones were used as resistant parents in crosses with the susceptible diploid clone DW 94-4235 (resistance score 1), obtained in a crossing programme performed in Młochów Research Centre. One hundred and forty progeny clones were obtained from the cross DW $94-4235 \times \mathrm{Sg} 2 / 7$ and 104 progeny clones were obtained from the cross DW $94-4235 \times$ Sg 3/3.

\section{Test for Nematode Resistance}

The test was performed according to Przetakiewicz and Milczarek (2017). The resistance screening was conducted in two independent phenotypic tests. Ten tubers per genotype were planted separately in pots with 11 of soil (Universal Kronenerde soil) containing nematode cysts $\left(5 \mathrm{eggs} \times \mathrm{ml}^{-1}\right.$ of soil) of either G. pallida $\mathrm{Pa} 2$ (5 tubers) or $\mathrm{Pa} 3$ (5 tubers). The pathotypes used for inoculation were the $\mathrm{Pa} 3$ population "Chavornay" and pathotype $\mathrm{Pa} 2$ obtained from the collection of the Federal Research Centre for Cultivated Plants, Germany (JKI). Plants were grown in a glasshouse for 3 months and then the plants (with soil) were removed and the cysts counted. The relative susceptibility of the tested accessions/progeny clones was calculated according to the following formula:

$($ Pf of tested sample $) /($ Pf of susceptible standard cultivar $) \times 100 \%$

where Pf is the mean number of cysts determined by counting all cysts from all replicates; cv. Desiree was used as a susceptible standard.

Resistance was scored on a 9-grade scale, where score 9 indicates the highest level of resistance according to the EU Council Directive 2007/33/EC. The progeny clone was regarded as resistant when the score was higher than 5-moderate resistance score (Table 1).

Table 1 Calculation of resistance score on basis of relative susceptibility

\begin{tabular}{|c|c|}
\hline Relative susceptibility (\%) & Resistance score \\
\hline$<1$ & 9 (very high) $^{\mathrm{a}}$ \\
\hline $1.1-3$ & 8 (high to very high) \\
\hline $3.1-5$ & 7 (high) \\
\hline $5.1-10$ & 6 (moderate to high) \\
\hline $10.1-15$ & 5 (moderate) \\
\hline $15.1-25$ & 4 (low to moderate) \\
\hline $25.1-50$ & 3 (low) \\
\hline $50.1-100$ & 2 (very low to low) \\
\hline$>100$ & 1 (very low) \\
\hline
\end{tabular}

a According to Przetakiewicz and Milczarek (2017) 


\section{Statistical Analyses}

The Pearson correlation coefficient for resistance to pathotypes $\mathrm{Pa} 2$ and $\mathrm{Pa} 3$ was performed with the STATISTICA data analysis software system, version 10 (www.statsoft.com).

\section{Results}

After inoculation with the G. pallida pathotypes $\mathrm{Pa} 2$ and $\mathrm{Pa} 3$, the mean cyst count over the replicates was established for each tested genotype. The cyst count ranged from 0 to 528 cysts for pathotype $\mathrm{Pa} 2$ and from 0 to 532 cysts for pathotype Pa3. The susceptible control (Desiree) developed on average 458 cysts of pathotype $\mathrm{Pa} 2$ and 468 cysts of pathotype Pa3. The mean number of cysts counted per tested genotype was used for calculation of resistance scores. The clone was regarded as resistant when the score was higher than 5 (under 45 and 47 cysts counted for $\mathrm{Pa} 2$ and $\mathrm{Pa} 3$, respectively).

Clone $\mathrm{Sg} 3 / 3$ was highly resistant to pathotype $\mathrm{Pa} 2$ (resistance score 8) and to pathotype $\mathrm{Pa} 3$ (resistance score 9). Clone $\mathrm{Sg} 2 / 7$ was highly resistant to pathotype $\mathrm{Pa} 2$ (resistance score 9) and resistant to pathotype Pa3 (resistance score 7).

Cyst count and the resistance score for each tested progeny clone are shown in

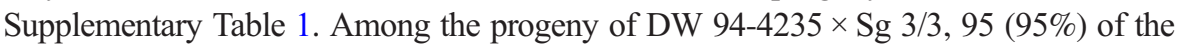
clones were resistant to pathotype $\mathrm{Pa} 2$ (resistance score $>5)$. Only $11(12 \%)$ of the clones were resistant to $\mathrm{Pa} 3$ (Fig. 1). From among 95 clones resistant to pathotype Pa2, 11 clones were resistant to pathotype Pa3. The Pearson correlation coefficient for resistance to pathotypes $\mathrm{Pa} 2$ and $\mathrm{Pa} 3$ was $r=0.26 *$ in population DW $94-4235 \times \mathrm{Sg} 3 / 3$.

Among the progeny of DW $94-4235 \times \mathrm{Sg} 2 / 7$, the distribution of resistance to pathotype $\mathrm{Pa} 2$ was bimodal (Fig. 2). In general, $23(17 \%)$ of the clones from this progeny were resistant to pathotype $\mathrm{Pa} 2$ whereas a total of 80 (61\%) of the clones were found to be resistant to $\mathrm{Pa} 3$ (Fig. 2). From among 80 clones resistant to pathotype Pa3, 15 clones were resistant to pathotype $\mathrm{Pa} 2$. The Pearson correlation coefficient for resistance to pathotypes $\mathrm{Pa} 2$ and $\mathrm{Pa} 3$ was $r=0.08$ in population DW 94-4235 $\times \mathrm{Sg} 2 / 7$.

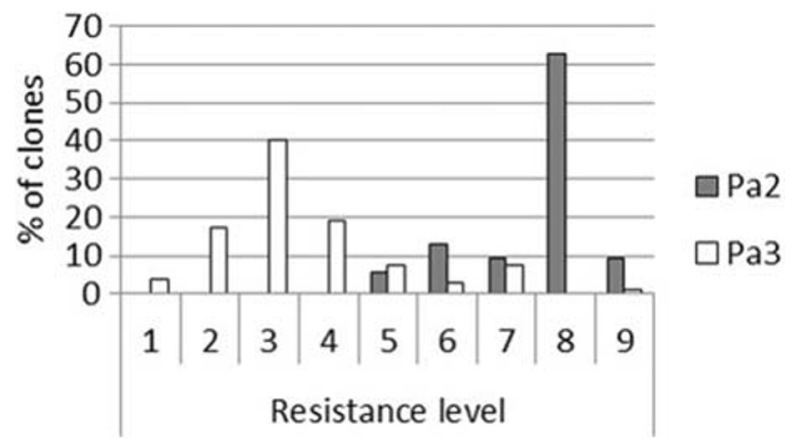

Fig. 1 Frequency distribution of resistance to pathotypes $\mathrm{Pa} 2$ and $\mathrm{Pa} 3$ of G. pallida in the progeny of DW 94$4235 \times \mathrm{Sg} 3 / 3$. Resistance level 9 indicates the highest level of resistance 


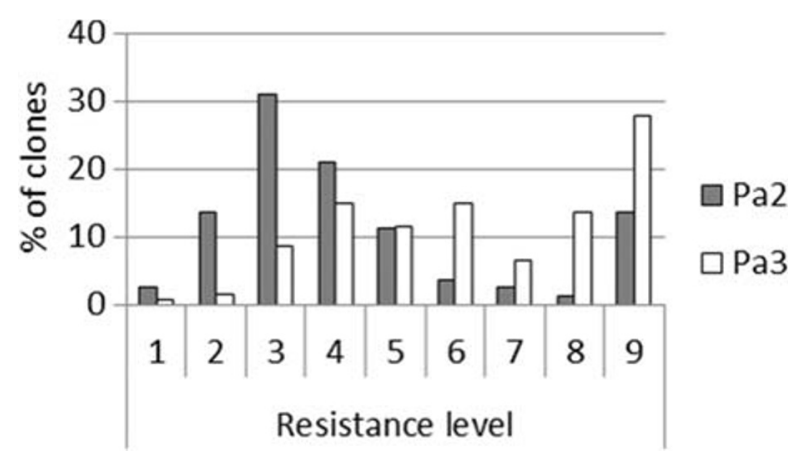

Fig. 2 Frequency distribution of resistance to pathotypes $\mathrm{Pa} 2$ and $\mathrm{Pa} 3$ of G. pallida in the progeny of DW 94$4235 \times \mathrm{Sg} 2 / 7$. Resistance level 9 indicates the highest level of resistance

\section{Discussion}

Cultivating resistant cultivars of potato is the most effective and environmentally safe method for protecting potato crops against pests and diseases. Potato breeding for resistance is partially based on introgression of resistance genes from wild potato species (Gebhardt and Valkonen 2001). Among Solanum spp. evaluated for nematode resistance, $S$. gourlayi was recognised as a source of resistance to G. pallida (Dalamu et al. 2012). Van Soest et al. (1983) concluded that both resistant and susceptible accessions can be found in the gene pool of $S$. gourlayi. Uhrig and Wenzel (1981) found that the percentage of resistant clones in the S. gourlayi hybrids was higher compared with the $S$. vernei hybrids. Chavez et al. (1988) in their research-derived hybrids of tetraploid $S$. gourlayi rated high resistance to $\mathrm{P} 4 \mathrm{~A}$, with $>50 \%$ resistant in crosses with $S$. tuberosum ssp. andigena, and over 97\% in crosses with ssp. tuberosum, but susceptible to P5A. In that investigation, two populations of G. pallida from South America were used, which are designated P4A and P5A according to the pathotype scheme of Canto-Saenz and de Scurrah (1977). The results of our work indicate that the evaluated accessions of $S$. gourlayi are sources for nematode resistance that can be incorporated into practical potato breeding programmes.

European populations of G. pallida are divided into three groups of pathotypes, namely $\mathrm{Pa} 1, \mathrm{~Pa} 2$ and $\mathrm{Pa} 3$, based on their different pathogenic characteristics (Kort et al. 1977). Many authors, while evaluating sources of resistance, treat the pathotypes $\mathrm{Pa} 2$ and $\mathrm{Pa} 3$ as one. Resistance to the G. pallida pathotypes $\mathrm{Pa} 2 / \mathrm{Pa} 3$ is used to indicate resistance to pathotypes $\mathrm{Pa} 2$ and/or Pa3 (Sattarzadeh et al. 2006). However, taking into account the results of this work, we conclude that resistance tests should be conducted independently for every pathotype. Although the evaluated resistant parental forms ( $g r l$ accessions) demonstrated resistance to both pathotypes $\mathrm{Pa} 2$ and $\mathrm{Pa} 3$, this resistance was segregated among the progeny clones. Figures 1 and 2 show the asymmetric distributions of resistances to each tested pathotype of G. pallida in the evaluated progenies. Most of the clones 
tested from the progeny of DW $94-4235 \times \mathrm{Sg} 3 / 3$ were highly resistant to pathotype $\mathrm{Pa} 2$ and susceptible to pathotype Pa3. In turn, most of the clones tested from the progeny of DW $94-4235 \times \mathrm{Sg} 2 / 7$ were highly resistant to pathotype $\mathrm{Pa} 3$ but susceptible to pathotype Pa2. The Pearson correlation coefficients for resistance to pathotypes $\mathrm{Pa} 2$ and $\mathrm{Pa} 3$ for these populations were low. The presented distributions of resistance scores (Figs. 1 and 2) indicate the quantitative nature of resistance to G. pallida. Furthermore, this resistance is specific to each pathotype and may be controlled by different genes. There is a need of further investigation of the genetic basis of this resistance.

Author's Contribution D.M. conceived and coordinated the project and co-wrote the paper. A.P.P. carried out phenotyping studies. B.F., B.T. and J.P. participated in the design of the studies and co-wrote the paper. All authors reviewed the manuscript.

Funding This work was partly supported by the project BH 4-3-00-6-02 of the Ministry of Agriculture and Rural Development.

\section{Compliance with Ethical Standards}

Conflict of Interest The authors declare that they have no conflict of interest.

Statement of Human and Animal Right This article does not contain any studies with human or animal subjects performed by any of the authors.

Open Access This article is licensed under a Creative Commons Attribution 4.0 International License, which permits use, sharing, adaptation, distribution and reproduction in any medium or format, as long as you give appropriate credit to the original author(s) and the source, provide a link to the Creative Commons licence, and indicate if changes were made. The images or other third party material in this article are included in the article's Creative Commons licence, unless indicated otherwise in a credit line to the material. If material is not included in the article's Creative Commons licence and your intended use is not permitted by statutory regulation or exceeds the permitted use, you will need to obtain permission directly from the copyright holder. To view a copy of this licence, visit http://creativecommons.org/licenses/by/4.0/.

\section{References}

Bradshaw JE, Hackett CA, Meyer RC, Milbourne D, McNicol JW, Phillips MS, Waugh R (1998) Identification of AFLP and SSR markers associated with quantitative resistance to Globodera pallida (Stone) in tetraploid potato (Solanum tuberosum subsp. tuberosum) with a view to marker-assisted selection. Theor Appl Genet 97:202-210

Bryan G, McLean K, Bradshaw J, De Jong W, Phillips M, Castelli L, Waugh R (2002) Mapping QTLs for resistance to the cyst nematode Globodera pallida derived from the wild potato species Solanum vernei. Theor Appl Genet 105:68-77

Bryan GJ, McLean K, Pande B, Purvis A, Hackett CA, Bradshaw JE, Waugh R (2004) Genetical dissection of $\mathrm{H} 3$-mediated polygenic PCN resistance in a heterozygous autotetraploid potato population. Mol Breed 14:105-116

Canto-Saenz MA, de Scurrah MM (1977) Races of the potato cyst nematode in the Andean region and a new system of classification. Nematologica 23:340-349

Caromel B, Mugniéry D, Kerlan MC, Andrzejewski S, Palloix A, Ellissèche D, Rousselle-Bourgeois F, Lefebvre V (2005) Resistance quantitative trait loci originating from Solanum sparsipilum act independently on the sex ratio of Globodera pallida and together for developing a necrotic reaction. MPMI 18: 1186-1194 
Castelli L, Bryan G, Blok VC, Ramsay G, Phillips MS (2005) Investigation of resistance specificity amongst fifteen wild Solanum species to a range of Globodera pallida and G. rostochiensis populations. Nematology 7:689-699

CGN gene bank descriptions (n.d.) https://cgngenis.wur.nl/AccessionDetails.aspx? ID=muwqtoir\&acnumber= CGN22342; https://cgngenis.wur.nl/AccessionDetails.aspx?acnumber=CGN17592)

Chavez R, Jackson MT, Schmiediche PE, Franco J (1988) The importance of wild potato species resistant to the potato cyst nematode, Globodera pallida, pathotypes $\mathrm{Pa} 4$ and $\mathrm{Pa} 5$, in potato breeding. I Resistance studies. Euphytica 37:9-14

Dalamu BV, Umamaheshwari R, Shrama R, Kaushik SK, Joseph TA, Singh BP, Gebhardt C (2012) Potato cyst nematode $(\mathrm{PCN})$ resistance: genes, genotypes and markers - an update. SABRAO J Breed Genet 44 : 202-228

de Galarreta R, Carrasco A, Salazar A, Barrena I, Iturritxa E, Marquinez R, Legorburu FJ, Ritter E (1998) Wild Solanum species as resistance sources against different pathogens of potato. Potato Res 41:57-68

Dunnett J (1961) Inheritance of resistance to potato root eelworm in a breeding line stemming from Solanum multidissectum Hawkes. In: Report of the Scottish plant breeding station, pp 39-46

EPPO Reporting Service (2012) Situation of Globodera pallida in Finland in 2011

EPPO Reporting service (2013) First report of Globodera pallida in Denmark

EPPO/OEPP (2004) Diagnostic protocols for regulated pests, European and Mediterranean plant protection organization. OEPP/EPPO Bull 34:309-314

Evans K, Trudgill DL (1992) Pest aspects of potato production. Part 1. The nematode pests of potato. In: Harris P (ed) The potato crop, 2nd edn. Chapman and Hall, London, pp 438-475

Gebhardt C, Valkonen JP (2001) Organization of genes controlling disease resistance in the potato genome. Annu Rev Phytopathol 39:79-102

Kort J, Ross H, Stone AR, Rumpenhorst HJ (1977) An international scheme for identifying and classifying pathotypes of potato cyst-nematodes Globodera rostochiensis and G. pallida. Nematologica 23:333-339

Nicol JM, Turner SJ, Coyne DL, den Nijs L, Hockland S, Tahna Maafi Z (2011) Current nematode threats to world agriculture. In: Jones J, Gheysen G, Fenoll C (eds) Genomics and molecular genetics of plantnematode interactions. Springer, Berlin, pp 21-43

Nježić B, Stare BG, Širca S, Grujic N (2014) First report of the pale potato cyst nematode Globodera pallida from Bosnia and Herzegovina. Plant Dis 98:575-575

Przetakiewicz A, Milczarek D (2017) Evaluation of potato cultivars and breeding lines for resistance to Globodera rostochiensis and Globodera pallida. Plant Breed Seed Sci 76:3-8

Sattarzadeh A, Achenbach U, Lübeck J, Strahwald J, Tacke E, Hofferbert HR, Rothsteyn T, Gebhardt C (2006) Single nucleotide polymorphism (SNP) genotyping as basis for developing a PCR-based marker highly diagnostic for potato varieties with high resistance to Globodera pallida pathotype Pa2/3. Mol Breed 18:301-312

Šrca S, Stare BG, Strajnar P, Urek G, Lautar IM (2012) First report of the pale potato cyst nematode Globodera pallida from Slovenia. Plant Dis 96:773-773

Smith IM, McNamara DG, Scott PR, Harris KM (1992) Quarantine pests for Europe. CAB Int \& EPPO

Strachan SM, Armstrong MR, Kaur A, Wright KM, Lim TY, Baker K, Jones J, Bryan G, Blok V, Hein I (2019) Mapping the $\mathrm{H} 2$ resistance effective against Globodera pallida pathotype $\mathrm{Pa}$ in tetraploid potato. Theor Appl Genet 132(4):1283-1294

Uhrig U, Wenzel G (1981) Solanum gourlayi Hawkes as a source of resistance against the white potato cyst nematode Globodera pallida Stone. Zeitschrift fuer Pflanzenzuechtung 86:148-157

van der Voort JR, Kanyuka K, van der Vossen E, Bendahmane A, Mooijman P, Klein-Lankhorst R, Stiekema W, Baulcombe D, Bakker J (1999) Tight physical linkage of the nematode resistance gene Gpa2 and the virus resistance gene $R x$ on a single segment introgressed from the wild species Solanum tuberosum subsp. andigena CPC 1673 into cultivated potato. MPMI 12:197-206

van der Voort JR, Van der Vossen E, Bakker E, Overmars H, Van Zandvoort P, Hutten R, Klein Linkhorst R, Bakker J (2000) Two additive QTLs conferring broad-spectrum resistance in potato to Globodera pallida are localized on resistance gene clusters. Theor Appl Genet 101:1122-1130

Van Soest LJM, Rumpenhorst HJ, Huijsman CA (1983) Resistance to potato cyst-nematodes in tuber-bearing Solanum species and its geographical distribution. Euphytica 32:65-74

Publisher's Note Springer Nature remains neutral with regard to jurisdictional claims in published maps and institutional affiliations. 